\title{
PENGEMBANGAN MEDIA PEMBELAJARAN KETERAMPILAN MEMBACA BERBASIS ANDROID POKOK PEMBAHASAN LEGENDA DESA-DESA DI MADURA PADA PEMBELAJARAN BAHASA INDONESIA KELAS VII SMP NEGERI SE-KABUPATEN BANGKALAN
}

\author{
Ahmad Jami'ul Amil ${ }^{1}$, Arief Setyawan ${ }^{2}$, Prita Dellia ${ }^{3}$ \\ 1,2Program Studi Pendidikan Bahasa dan Sastra Indonesia, Universitas Trunojoyo Madura \\ ${ }^{3}$ Program Studi Pendidikan Informatika, Universitas Trunojoyo Madura \\ E-mail: ahmadamil@trunojoyo.ac.id
}

\begin{abstract}
Abstrak
Penelitian ini adalah penelitian pengembangan dengan menggunakan konsep pengembangan Borg and Gall dengan mengadopsi tujuh langkah dari konsep tersebut yaitu pada tahapan revisi. Rumusan masalah dalam penelitian ini adalah bagaimana pengembangan Media pembelajaran berbasis android pokok bahasan desa-desa di Madura. Media ini mengangkat tokoh Jokotole sebagai tokoh sentral untuk mengungkap legenda desa-desa berdasarkan pada perjalanan Jokotole. Pengangkatan tokoh Jokotole karena cenderung bisa diterima oleh seluruh lapisan masyarakat Madura dari Kabupaten Bangkalan sampai Kabupaten Sumenep. Media android dikonsep dengan memudahkan siswa dalam belajar terutama membaca. Rangkaian penelitian meliputi kajian tekstual, pembuatan konsep story board, prototype media, validasi ahli media, validasi ahli materi, revisi, dan uji coba media pembelajaran (melihat dari unsur kemudahan, kemenarikan, uji kemampuan membaca siswa), penarikan simpulan, dan rekomendasi bagi penyedia hibah penelitian, dan sekolah sebagai objek penelitian.
\end{abstract}

Kata kunci: pengembangan, media android, legenda, Jokotole, membaca.

Abstract

This research is a development study using the Borg and Gall development concept by adopting the seven steps of the concept at the revision stage. The formulation of the problem in this research is how the development of Android-based learning media is the subject of villages in Madura. This media raised Jokotole as a central figure to uncover the legends of villages based on Jokotole's journey. The appointment of the Jokotole figure was because it tended to be accepted by all levels of Madura society from Bangkalan to Sumenep. Android media conceptualized by allowing students to learn, especially reading. The series of studies include textual studies, conceptualization of story boards, media prototypes, validation of media experts, validation of material experts, revisions, and testing of learning media (looking at the elements of ease, attractiveness, student reading ability test), drawing conclusions, and recommendations for providers research grants, and schools as research objects.

Keywords: development, android media, legend, Jokotole, reading.

\section{PENDAHULUAN}

Penggunaan gadget pada anak-anak memang sudah tidak dapat dihindarkan lagi. Kondisi dilematik jika melarang anak menggunakan gadget di zaman yang serba teknologi saat ini. Hal tersebut karena dapat berpengaruh pada keterlambatan penguasaan anak (gaptek: gagap teknologi) terhadap teknologi yang tentu dibutuhkannya dalam berkomunikasi dan berinteraksi saat mereka dewasa. Sebagai orang tua ataupun pendidik, hal yang lebih efektif dan bisa dilakukan adalah dengan membatasi serta mengarahkannya ke arah yang positif dan dapat menunjang proses belajar anak. Salah satunya adalah dengan memanfaatkan gadget tersebut sebagai media pembelajaran keterampilan membaca.

Maryunita (2017) pernah meneliti mengenai manfaat aplikasi Google Japanese Input serta aplikasi pendukung lainnya, dalam upaya meningkatkan kemampuan keterampilan membaca peserta didik dan memahami isi teks bahasa Jepang. Dengan memanfaatkan teknologi terkini yang sesuai dengan tujuan pembelajaran, maka akan dapat kembali meningkatkan minat peserta didik untuk belajar bahasa Jepang dan menumbuhkan budaya literasi. Senada dengan hal tersebut, Busran dan Fitriyah (2015) juga 
pernah meneliti mengenai aplikasi belajar membaca pada anak prasekolah berbasis smartphone android yang mendapati hasil bahwa software aplikasi dapat digunakan sebagai alat bantu ajar dalam bentuk game edukasi berbasis smartphone android dengan teknologi mobile learning.

Berdasakan fakta-fakta dari pesatnya perkembangan teknologi smartphone berbasis android, kebermaanfaatan, serta dampak positifnya terhadap proses belajar anak, penulis bermaksud melakukan penelitian pengembangan media agar smartphone andoid tersebut berdaya guna optimal bagi pembelajaran membaca pada anak-anak. Adapun lingkup bahan bacaan yang digunakan fokus pada sumber legenda-legenda daerah, khususnya di wilayah Bangkalan, Madura. Hal ini dimaksudkan agar lebih menarik minat anak sekaligus secara tidak langsung mengenalkannya pada sejarah, aneka ragam cerita rakyat, serta kebudayaan-kebudayaan di daerahnya.

\section{METODOLOGI PENELITIAN}

Penelitian ini merupakan penelitian pengembangan atau Research \& Development (R\&D). Sugiyono (2014: 297) menjelaskan bahwa Research and Development adalah metode penelitian yang digunakan untuk menghasilkan produk tertentu, dan digunakan untuk menguji keefektifan produk tersebut. Jadi, penelitian dan pengembangan merupakan metode penelitian yang digunakan untuk mengembangan atau memvalidasi produk-produk yang digunakan dalam pendidikan dan pembelajaran.

Menurut Borg and Gall (dalam Hasyim, 2016: 87) menyatakan bahwa ada sepuluh langkah pelaksanaan teknik penelitian dan pengembangan, Langkah-langkah $\mathrm{R} \& \mathrm{D}$ yang diajukan Borg and Gall disederhanakan menjadi 7 tahapan. Menurut Emzir dalam bukunya modifikasi Sugiyono (2014: 75) menjelaskan bahwa penelitian tesis maupun disertasi sebaiknya dibatasi hingga pada tahap penelitian skala dikarenakan apabila dilakukan sampai pada tahap ke sepuluh akan membutuhkan biaya dan waktu yang sangat lama.

Penelitian ini merupakan penelitian pengembangan dengan menggunakan model pengembangan yang dikembangkan oleh Borg and Gall. Model pengembangan Borg and Gall terdiri dari sepuluh langkah yang dibatasi hingga langkah ke tujuh oleh peneliti yaitu tahap revisi. Model pengembangan Borg and Gall dipilih karena dapat digunakan untuk mengembangkan lembar kerja siswa yang akan dikembangkan. Pengembangan ini dilakukan menggunakan pengembangan Borg and Gall dengan modifikasi Sugiyono dalam Emzir (2008: 275).



Gambar 3.1 Desain Model Pengembangan Borg and Gall (Emzir, 2008: 275)

Produk yang dikembangkan dalam penelitian ini adalah Pengembangan media pembelajaran android legenda desa-desa Madura untuk pembelajaran membaca pada pembelajaran bahasa Indonesia. Media pembelajaran berbentuk aplikasi android diharapkan dapat memotivasi minat membaca siswa pada materi cerita rakyat. Legenda desa-desa dikemas melalui ceritacerita media android dalam bentuk aplikasi. Sehingga wawasan siswa semakin luas, tidak terpaku pada materi yang diajarkan.

\section{HASIL PENELITIAN}

\section{Konsep Pengembangan Media \\ Pembelajaran}

Penelitian ini adalah penelitian pengembangan media pembelajaran bahasa Indonesia untuk keterampilan membaca dengan tujuan untuk memudahkan proses pembelajaran dan transfer pendidikan karakter disertai dengan perawatan, pemahaman cerita rakyat dan legenda. Desain yang digunakan adalah Borg and gall ada tujuh tahapan penelitian yaitu, identifikasi masalah, pengumpulan informasi, desain produk, uji coba produk, revisi desain, validasi desain, dan revisi produk. Media pembelajaran yang dikembangkan tersebut bisa digunakan pada handphone android dan komputer, sedangkan pengembangannya pada kemenarikan dan konten kemudahan pengoperasionalan media pembelajaran berbasis android.

\section{Media Jokotole Acareta}

Media Jokotole Acareta disusun berpedoman pada cerita Jokotole, media pembelajaran disusun berdasarakan aplikasi unity 
dan media Jokotole bisa dipasangkan pada media android dan PC (laptop). Dalam penyusunan media aplikasi android memiliki beberapa tahapan yaitu, konsep (story board), penyusunan menggunakan aplikasi unity, validasi media pembelajaran (meliputi tampilan, kemudahan, dan desain), validasi materi (certa rakyat jokotole yang ada di dalam aplikasi), revisi, dan uji coba ke sekolah.

\section{Validasi Media dan materi pembelajaran}

Validasi media pembelajaran didalamnya adalah komponen teknologi dan desain pesan, suara musik, kemudahan instalasi, dan warna gambar yang harus diperbaiki. Media pembelajaran yang disusun sudah menjadi sebuah aplikasi yang utuh sebelum divalidasi oleh ahli media dan ahli materi. Setelah ahli media memberi masukan selanjutnya memvalidasi materi. Validasi materi terkait konten materi cerita rakyat mulai dari Bangkalan, Socah sampai dengan Ujung Piring Bangkalan. Hasil validasi materi ditemukan bahwa ada ketidaksinkronan perjalanan jokotole dalam media pembelajaran yaitu setelah Jokotole berjalan melewati desa jambu jokotole langsung ke Sampang dan ke Sumenep. Sementara di dalam media pembelajaran dari Jambu ke bancaran dan langsung ke Ujung Piring. Dari validasi materi tersebut peneliti kembalikan konsep awal bahwa media pembelajaran ini dikonsep sesuai perjalanan cerita Jokotole di Bangkalan. Hasil validasi dari ahli materi akan dijadikan rekomendasi penelitian yang akan datang dengan tujuan keluasan dan jangkauan cerita rakyat Jokotole.

\section{Kemampuan Membaca siswa}

Mengukur kehandalan media dan mengukur kemampuan membaca siswa SMP Negeri se-Kabupaten Bangkalan, peneliti mengambil dua sampel sekolah yaitu di SMP Negeri 2 Bangkalan dan SMP Negeri 1 Socah Bangkalan dengan mengambil sampel 15 orang siswa di kelas VII semester ganjil tahun 20192020 pada materi cerita rakyat pada pertemuan ke-empat pembelajaran bahasa Indonesia.

Tabel 4.1 Kemampuan membaca siswa SMPN 1 Socah Bangkalan

\begin{tabular}{|c|l|c|c|c|}
\hline NO & \multicolumn{1}{|c|}{ NAMA } & (KPM) & A & B \\
\hline 1 & Achmad Aditya F & 120 & 30 & 50 \\
\hline 2 & Moh Fajar Hamdan & 120 & 10 & 40 \\
\hline 3 & Moh Amir Firdaus & 120 & 40 & 60 \\
\hline 4 & Bram Shohibul Hizer & 120 & 40 & 20 \\
\hline
\end{tabular}

\begin{tabular}{|c|l|c|c|c|}
\hline 5 & Deni & 120 & 20 & 30 \\
\hline 6 & Ach Faizal & 120 & 40 & 20 \\
\hline 7 & Moh Roffar Effendi & 60 & 40 & 40 \\
\hline 8 & Moh. Umar Faruq A & 120 & 20 & 50 \\
\hline 9 & Zainul Rohman & 120 & 20 & 30 \\
\hline 10 & Syahrul Muharrom & 180 & 20 & 20 \\
\hline 11 & Intan Maulidia & 120 & 30 & 60 \\
\hline 12 & Siti Ayuningsih & 120 & 20 & 70 \\
\hline 13 & Rasmiyatul Hasanah & 60 & 30 & 30 \\
\hline 14 & Mega Yulianti Putri & 60 & 20 & 40 \\
\hline 15 & Moh Nisen & 120 & 20 & 20 \\
\hline 16 & Misbahus Surur & 120 & 30 & 50 \\
\hline 17 & Misbehul Munir & 60 & 10 & 20 \\
\hline 18 & Moh Arif & 120 & 10 & 20 \\
\hline 19 & Moh Aldi Aminallah & 120 & 10 & 20 \\
\hline 20 & Robi Afdol & 120 & 40 & 60 \\
\hline 21 & Horul Anwar & 120 & 20 & 40 \\
\hline 22 & Siti Halimatus sakdiyah & 120 & 40 & 70 \\
\hline 23 & Rizky Putri Auliyak & 120 & 40 & 70 \\
\hline 24 & Wulandari & 120 & 50 & 50 \\
\hline 25 & Nur'aini & 120 & 10 & 40 \\
\hline 26 & Torikotul Ilmiyah & 120 & 40 & 10 \\
\hline 27 & Dea Shafira & 120 & 30 & 50 \\
\hline 28 & Siti Jemaliya & 120 & 30 & 50 \\
\hline 29 & Luluk Il Makmunah & 120 & 30 & 50 \\
\hline 30 & Dimas Abdi Wahono & 180 & 30 & 0 \\
\hline 31 & M. Fredi Kurniawan & 120 & 10 & 10 \\
\hline 32 & Moh Komaruddin & 180 & 10 & 0 \\
\hline & RATA-RATA & 118.2 & 26.3 & 37.2 \\
\hline
\end{tabular}

Hasil perhitungan kecepatan membaca siswa disimpulkan bahwa rata-rata kecepatan membaca mereka adalah 118 KPM dan pengerjaan soal dengan rata-rata 16,3 untuk paket soal A dan 37,2 untuk paket soal B. Dari data tersebut kemampuan membaca pemahaman mereka mengalami peningkatan di paket soal B. Secara keseluruhan media pembelajaran Jokotole Acareta dapat diterapkan dengan baik dan digunakan siswa dengan mudah.

\section{Rekomendasi}

Rekomendasi dari penelitian ini adalah;

a. Media pembelajaran aplikasi android sangat efektif untuk diterapkan dalam pembelajaran bahasa Indonesia tingkat dasar di SMP seKabupaten Bangkalan;

b. Perlu pengembangan lanjutan terhadap media pembelajaran berbasis android karena masih pada seputar cerita Jokotole wilayaah Kabupaten Bangkalan;

c. Media pembelajaran bisa diaplikasikan di dalam PC (laptop) dan handphone android;

d. Perkembangan penelitian ke arah lebih baik jika semua sekolah di wilayah Bangkalan membuka diri untuk pengembangan kemampuan membaca siswanya melalui media pembelajaran tersebut; 
e. Pengembangan media pembelajaran Jokotole Acareta bisa lebih handal dengan menggunakan database sehingga hasil penilaian kemampuan membaca dapat terekam melalui sistem database.

\section{SIMPULAN}

Legenda desa-desa di Madura berjumlah puluhan mulai dari Bangkalan, Sampang, Pamekasan, dan Sumenep. Dari puluhan legenda desa-desa tersebut memiliki hal positif terkait dengan kepahlawanan, pendidikan, religius, dan kepatuhan pada orang tua. Dari hal tersebut maka peran pembelajaran menjadi signifikan sehingga dari legenda desa-desa yang fokus pokok bahasannya mengenai jokotole dijadikan sumber dan pijakan muatan dalam pengembangan media pembelajaran berbasis android. Model media yang dikembangkan adalah legenda desa-desa dari perjalanan tokoh jokotole sampai akhir dari perjuangnnya. Model media tersebut dikembangkan berdasarkan konten materi dan pemahaman terhadap cerita melalui membaca dari media android tersebut.

\section{DAFTAR PUSTAKA}

Ardiansyah, Firdan. (2011). Pengenalan Dasar Android Programming. Depok: Biraynara.

Arsyad, Azhar. (2011). Media Pembelajaran. Jakarta: PT. Raja Grafindo Persada.

Arsyad, Azhar. (2013). Media Pembelajaran. Jakarta: PT. Raja Grafindo Presada.

Busran dan Fitriyah. (2015). Perancangan Permainan (Game) Edukasi Belajar Membaca pada Anak Prasekolah Berbasis Smartphone Android (Studi Kasus: Taman Kanak-Kanak Ikal Iqra Padang Selatan). Jurnal Teknoif, 3(1), 62-70.

Endraswara, S. (2013). Folklor Nusantara: Hakikat, Bentuk, dan Fungsi. Yogyakarta: Penerbit Ombak.

Fatmawati, Ira \& Ikwan, Wakhid Khoirul. (2012). Kemampuan Dasar Keilmuan Bahasa Indonesia. Bangkalan: UTM Press.
Hamdani. (2011). Strategi Belajar Mengajar. Bandung: Pusaka Setia.

Hilmiyatun dan Satrya, D. (2015). Dewi Rengganis (Kajian Antropologi Sastra Levi-Strauss). Jurnal Educatio, 10(2), 449-462.

John D. Latuheru. (1988). Media Pembelajaran dalam proses Belajar Mengajar Masa Kini. Jakarta: Depdikbud.

Kristanto, M. (2014). Pemanfaatan Cerita Rakyat Sebagai Penanaman Etika untuk Membentuk Pendidikan Karakter Bangsa. Mimbar Sekolah Dasar, 1(1), 59-64.

Maryunita, Ramaniar. (2017). Pemanfaatan Aplikasi Google Japanese Input Dalam Meningkatkan Minat dan Kemampuan Membaca Teks Bahasa Jepang. Japanedu: Jurnal Pendidikan dan Pengajaran Bahasa Jepang, 2(1), 20-28.

Prasetyono, Tri. (2010). Cerita Rakyat Jawa Timur dan Madura 1. Jakarta: CV Sinar Cemerlang Abadi.

Priyanta, F. (2011). Pemrograman Android untuk Pemula. Jakarta: Cerdas Pustaka.

Safaat. (2012). Pemrograman aplikasi mobile smartphone dan tablet PC berbasis android, Bandung: Penerbit Informatika

Slamet, St. Y. (2009). Dasar-Dasar Keterampilan Berbahasa Indonesia. Surakarta: UNS Press.

Sugiyono dalam Emzir. (2008). Penelitian Pengembangan R \& D. Jakarta: Rajawali Press.

Sukiman. (2012). Pengembangan Media Pembelajaran. Yogyakarta: Pedajogja.

Sutopo, B. dan Mustofa, A. (2015). Kearifan Lokal dalam Cerita Rakyat Pacitan. Surakarta: Oase Pustaka.

Tarigan, Henry Guntur. (2008). Membaca Sebagai Suatu Keterampilan Berbahasa. Bandung: Angkasa. 